\title{
Resistome characterization of extended-spectrum beta-lactamase (ESBL)-producing Escherichia coli isolated from wastewater treatment utilities in Oregon
}

Maeghan Easler ${ }^{\mathrm{a},}{ }^{\mathrm{i}}$, Clinton Cheney ${ }^{\mathrm{a}, \uparrow}$, Jared D. Johnson ${ }^{\mathrm{b}}$, Marjan Khorshidi Zadeh ${ }^{\mathrm{a}}$, Jacquelynn N. Nguyen ${ }^{a}$, Sue Yee Yiu ${ }^{a}$, Joy Waite-Cusic ${ }^{b}$, Tyler S. Radniecki ${ }^{a}$, Tala Navab-Daneshmand ${ }^{a}{ }^{\text {,* }}$

a $105 \mathrm{SW} 26^{\text {th }} \mathrm{St}, 116$ Johnson Hall, School of Chemical, Biological, and Environmental Engineering, Oregon State University, Corvallis, OR 97331, United States

b 3051 SW Campus Way, Department of Food Science and Technology, Oregon State University, Corvallis, OR 97331, United States

${ }^{\dagger}$ These authors contributed equally to this work.

*Corresponding author: tala.navab@oregonstate.edu

\begin{abstract}
Infections resistant to broad spectrum antibiotics due to the emergence of extended-spectrum beta-lactamase (ESBL)-producing Enterobacteriaceae is of global concern. This study characterizes the resistome (i.e., entire ecology of resistance determinants) of 11 ESBLproducing Escherichia coli isolates collected from eight wastewater treatment utilities across Oregon. Whole genome sequencing was performed to identify the most abundant antibiotic resistance genes including ESBL-associated genes, virulence factors, as well as their sequence types. Moreover, the phenotypes of antibiotic resistance were characterized. ESBL-associated genes (i.e., $b l a_{\mathrm{CMY}}, b l a_{\mathrm{CTX}}, b l a_{\mathrm{SHV}}, b l a_{\mathrm{TEM}}$ ) were found in all but one of the isolates with five isolates carrying two of these genes ( 4 with $b l a_{\mathrm{CTX}}$ and $b l a_{\mathrm{TEM}} ; 1$ with $b l a_{\mathrm{CMY}}$ and $b l a_{\mathrm{TEM}}$ ). The атр $C$ gene and virulence factors were present in all the $E$. coli isolates. Across all the isolates, 31 different antibiotic resistance genes were identified. Additionally, all E. coli isolates harbored phenotypic resistance to beta-lactams (penicillins and cephalosporins), while eight of the 11 isolates carried multi-drug resistance phenotypes (resistance to three or more classes of antibiotics). Findings highlight the risks associated with the presence of ESBL-producing E. coli isolates in wastewater systems that have the potential to enter the environment and may pose direct or indirect risks to human health.
\end{abstract}

Keywords: Antibiotic resistance, E. coli, extended-spectrum beta-lactamases, wastewater, whole genome sequencing

\section{INTRODUCTION}

Emergence of bacterial infections resistance to antibiotics, including beta-lactams, is a global public health threat. Resistance to broad-spectrum beta-lactams, such as ampicillin and $3^{\text {rd }}$ and $4^{\text {th }}$ generation cephalosporins, by extended-spectrum beta-lactamase (ESBL)-producing Enterobacteriaceae is an emerging concern even in areas with high restrictions on antibiotic consumption, such as Norway (Jørgensen et al. 2017). Infections with ESBL-producing Enterobacteriaceae are shown to increase the risk of hospitalization, likelihood of discharge to a chronic care facility, and in-hospital mortality (Schwaber et al. 2006). ESBL-producing species are characterized by their ability to hydrolyze a broad spectrum of beta-lactam antibiotics, including oxyimino cephalosporins, monobactams, and penicillins. ESBLs are confirmed as the resistance mechanism by verifying that beta-lactamase inhibitors, clavulanic acid or tazobactam, restore the sensitivity to the beta-lactam (Bush and Fisher 2011). Development of novel beta- 
lactams has been ineffective to reduce the spread of ESBL-producers; in fact, selective pressure of novel antibiotics has resulted in the evolution of more pernicious beta-lactamases (Bradford 2001).

ESBL-associated genes are found in many species of Enterobacteriaceae, especially in Escherichia coli, a primary indicator of fecal bacterial contamination (Palucha et al. 1999). Among clinical isolates of ESBL-producing E. coli from various countries, including Indonesia, Iran, Korea, and the United States, $b l a_{\text {СтХ-M }}$ has been reported as the most common ESBL gene with bla $_{\mathrm{CTX} \text {-M-15 }}$ the most prevalent subtype (Park et al. 2009; Sidjabat et al. 2009; Severin et al. 2010; Haghighatpanah et al. 2016). In addition, many of the ESBL-producing E. coli carry virulence factors that can enhance their pathogenicity (Jiang et al. 2019). An example of a virulence factor is tellurite resistance, encoded by genes such as ter $C$, which has been implicated in bacterial resistance to phagocytosis and oxidative stress and contributing to prolonged urinary tract infections (Valková et al. 2007; Turkovicova et al. 2016). Moreover, ESBL genes are often encoded on plasmids (i.e., mobile genetic elements) and hence, can easily spread via horizontal gene transfer (Haenni et al. 2018; Liu et al. 2019). In addition, ESBL-producers are commonly resistant to other antibiotics, including gentamicin, sulfamethoxazole-trimethoprim, and ciprofloxacin, resulting in fewer clinical treatment options (Schwaber et al. 2005). Furthermore, ESBL-producing E. coli are reportedly more likely to be multi-drug resistance (i.e., resistant to three or more classes of antibiotics) than non ESBL-producers (Blaak et al. 2015; Jørgensen et al. 2017). The resistome (i.e., entire ecology of resistance determinants) of ESBL-producing $E$. coli is not clearly understood and further knowledge is needed to enable development of treatment options for ESBL-producing $E$. coli infections.

Although ESBL-producers have been primarily observed and described in clinical settings, ESBL genes and the bacterial strains that harbor them are also found in many environmental reservoirs including agricultural soils, livestock, and surface water (Ben Said et al. 2015; Blaak et al. 2015; Haenni et al. 2018). Wastewater treatment plants are also major reservoirs and sources of antibiotic-resistant bacteria and their determinant antibiotic resistance genes (ARGs) (Manaia et al. 2018; Alexander et al. 2020). Recently, ESBL-producing E. coli were detected in all the samples collected in a wastewater monitoring study in Germany (Schmiege et al. 2021). Similar to clinical settings, bla $a_{\text {CTX-M }}$ genes are common ESBL determinants in wastewater systems (Paulshus et al. 2019; Schages et al. 2020). Most of the studies on ESBL-associated genes in wastewater systems are from Europe; however, there is a limited knowledge regarding ESBL-producing E. coli in wastewater utilities in the United States. With growing attention to wastewater-based epidemiology as an important public health surveillance framework, understanding the resistome of ESBL-producing E. coli in wastewater treatment systems is critical (Riquelme et al. 2021).

This study characterizes the resistome of 11 ESBL-producing E. coli isolates collected from various wastewater treatment utilities across the state of Oregon. We used whole genome sequencing (WGS) to determine the antibiotic resistance genotypes of ESBL-producing E. coli isolates, their sequence types (STs), ARGs including ESBL-associated genes as well as virulence factors. Moreover, the phenotypes of antibiotic resistance were characterized. The significance and originality of this study is resistome characterization of ESBL-producing E. coli isolates in the U.S. wastewater treatment systems that have the potential to enter the environment and pose risks to human health.

\section{MATERIALS AND METHODS}




\section{E. coli isolation and antibiotic resistance phenotype determination}

E. coli isolates were collected from eight wastewater treatment utilities in Oregon as described previously (Khorshidi-Zadeh et al. submitted). Briefly, wastewater influent, secondary effluent, final effluent, and treated biosolids were collected from 17 wastewater treatment utilities over winter and summer in 2019 and 2020. To isolate $E$. coli colonies, collected samples were vacuum filtered or streaked directly onto m-TEC ChromoSelect agar (Sigma Aldrich, St. Louis, MO) plates and then confirmed by fluorescence on MacConkey agar with MUG (Hardy Diagnostics, Santa Maria, CA). Over the course of the study, 1143 E. coli colonies were isolated. Collected E. coli colonies were tested for the production of ESBL enzymes by measuring the zones of inhibition surrounding disks containing cefotaxime (30 $\mu \mathrm{g})$, ceftazidime $(30 \mu \mathrm{g})$, cefotaxime/clavulanic acid (30/10 $\mu \mathrm{g})$, and ceftazidime/clavulanic acid (30/10 $\mu \mathrm{g})(\mathrm{BD}$ Diagnostics, Sparks, MD) (CLSI 2020). A difference in zone of inhibition of $\geq 5 \mathrm{~mm}$ diameter between antibiotic and antibiotic-acid disks indicated the production of ESBL enzymes. An internal quality control and E. coli ATCC 25922 strains were used as positive and negative controls, respectively. The phenotypic antibiotic resistance of the isolates to a series of betalactam antibiotics, including penicillins, $1^{\text {st }}-4^{\text {th }}$ generation cephalosporins, and carbapenems were tested using the AST-GN99 card with a VITEK 2 system (bioMérieux, Marcy-l'Étoile, France) according to manufacturer's instructions. The AST-GN99 card includes other classes of antibiotics (i.e., aminoglycosides, quinolones, tetracycline, nitrofuran, and sulfonamide) that supported the classification of multi-drug resistance phenotypes. Overall, 13 E. coli wastewater isolates were originally classified as ESBL-producers (Khorshidi-Zadeh et al. submitted); however, two of these isolates could not be confirmed as ESBL-producers using the AST-GN99 cards. Therefore, a total of 11 isolates were included in the present study. Details about the samples associated with these isolates are listed in Table S1.

\section{Whole genome sequencing and bioinformatic analysis}

Freezer stocks were streaked onto tryptic soy agar (TSA; Hardy Diagnostics, Santa Maria, CA) and grown for 24 hours at $37{ }^{\circ} \mathrm{C}$ before being transferred to tryptic soy broth (TSB, Hardy Diagnostics, Santa Maria, CA). DNA was extracted from TSB cultures following manufacturer's instructions for the DNeasy Blood and Tissue kit (Qiagen, Carlsbad, CA). Purified DNA was quantified and quality checked using a Qubit 4 (Invitrogen, Carslbad, CA) and Nanodrop (Thermo Fisher, Waltham, MA). DNA samples were submitted to the Oregon State University's Center for Quantitative Life Sciences (Corvallis, OR) for library preparation using the plexWell $^{\text {TM }} 96$ kit (seqWell, Beverly, MA). Libraries were sequenced on a MiSeq 3000 instrument (Illumina, San Diego, CA), employing paired-end 150 base reads. Duplicate libraries of each isolate were prepared to meet the minimum sample requirement of the plexWell ${ }^{\mathrm{TM}} 96 \mathrm{kit}$.

Demultiplexed reads were quality assessed using FastQC v0.11.8 (Andrews et al. 2012) and sequencing adapters were removed using Trimmomatic v0.40 (Bolger et al. 2014). Duplicate reads were concatenated into single forward and reverse FASTQ files and uploaded to the PATRIC platform for whole genome assembly and annotation using the "Comprehensive Genome Analysis" service (Davis et al. 2019). The resulting draft genome assemblies and annotation files were used for all downstream analyses.

\section{Multi-locus sequence typing and phylogenetic analysis}

STs were determined from draft genome assemblies based on internal fragments of seven core genes (i.e., $a d k$, fum $C, \operatorname{gyr} B, i c d, m d h, p u r A$, and $r e c A$ ) using the Center for Genomic 
Epidemiology (CGE) server (Larsen et al. 2012). A phylogenetic tree was created based on the concatenated sequences of the seven ST core genes' fragments using the PhyML 3.1 MaximumLikelihood model with 100 rounds of bootstrapping using the SeaView platform (Wirth et al. 2006; Gouy et al. 2010; Guindon et al. 2010).

\section{Identification of ARGs and virulence factors}

ARGs were identified using NCBI's AMRFinderPlus with minimum nucleotide identity of $90 \%$ and a minimum coverage of $50 \%$ (Feldgarden et al. 2019). Virulence factors were found using VirulenceFinder 2.0, with minimum nucleotide identity set to $90 \%$ and a minimum coverage of $60 \%$ for each (Joensen et al. 2014). Percent identities of amino acid sequences of AmpC were compared using Clustal Omega (Madeira et al. 2019).

\section{Data availability}

The sequenced genomes have been deposited at the NCBI Sequence Read Archive (NCBI SRA) with the study identifier PRJNA767748.

\section{RESULTS}

\section{Antibiotic resistance phenotypes of $E$. coli isolates}

All 11 ESBL-producing E. coli isolates were resistant to at least one penicillin and several of the cephalosporin class beta-lactam antibiotics tested (Figure 1). In the penicillin class, all 11 E. coli isolates were resistant to ampicillin, and one isolate $(\mathrm{G})$ was resistant to amoxicillin complexed with the beta-lactamase inhibitor clavulanic acid. Isolate $\mathrm{G}$ also demonstrated intermediate resistance to piperacillin/tazobactam complex, while all other isolates $(n=10)$ were susceptible. Six of the $11 \mathrm{E}$. coli isolates were resistant to all four generations of tested cephalosporins (i.e., first: cefazolin, second: cefuroxime, third: ceftriaxone, fourth: cefepime). The other five E. coli isolates carried phenotypic resistance to three generations of cephalosporins, while two demonstrated intermediate resistance to the fourth generation cefepime. None of the $E$. coli isolates displayed resistance to the tested carbapenems (i.e., ertapenem, imipenem, meropenem).

Concerningly, eight of the $11 \mathrm{E}$. coli isolates were phenotypically multi-drug resistance (MDR) with resistances to three or more classes of antibiotics (Figure 1). Including beta-lactams, four of the $E$. coli isolates were phenotypically resistant to five classes of antibiotics (isolates $\mathrm{G}$, $\mathrm{I}, \mathrm{J}$, and $\mathrm{H}$ ). Tetracycline resistance was the most common detected non-beta-lactam antibiotic resistance $(n=10)$ and was observed in all the MDR E. coli isolates. Eight of the isolates were resistant to trimethoprim/sulfamethoxazole, but sensitive to nitrofurantoin. Five were resistant to both quinolones (ciprofloxacin and levofloxacin), and four were resistant to both aminoglycosides (gentamycin or tobramycin) tested. 


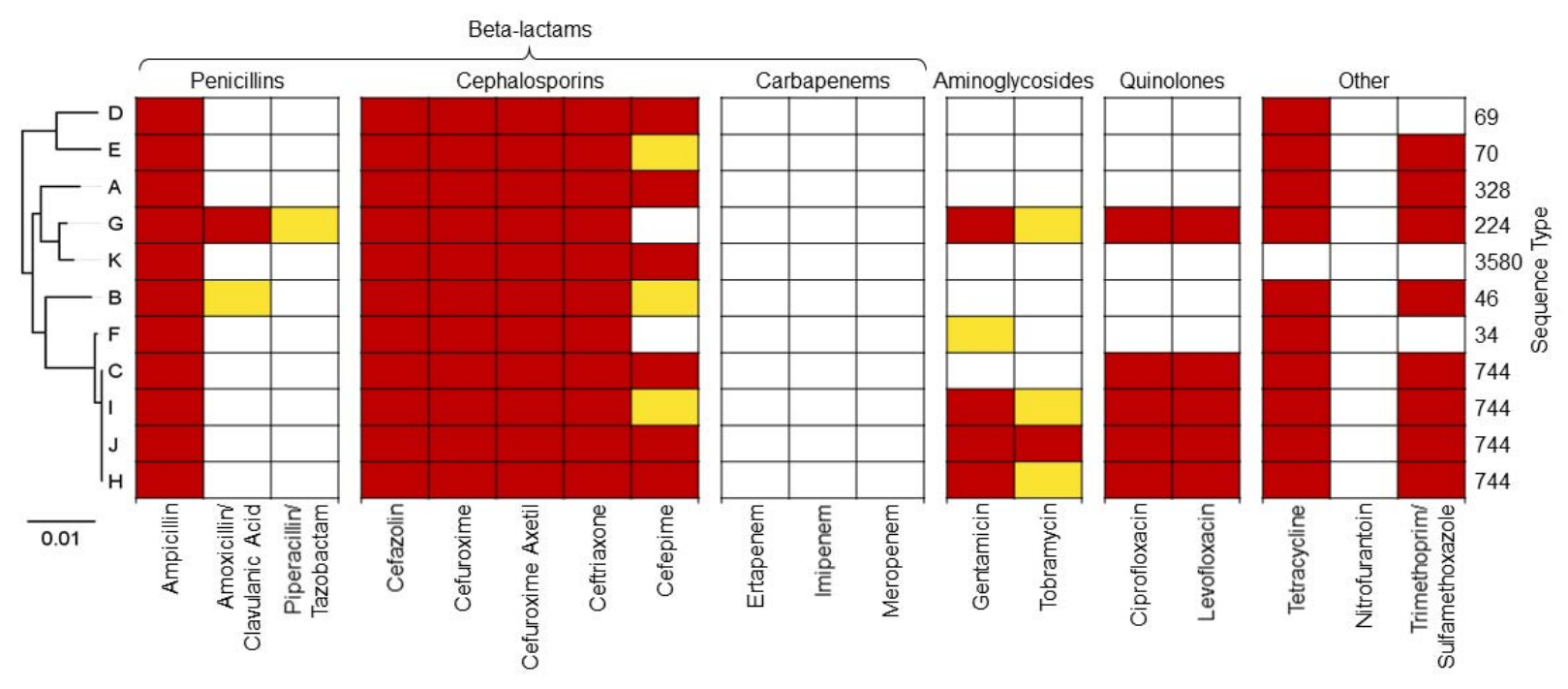

Figure 1. Antibiotic susceptibility phenotypes of ESBL-producing E. coli isolates to betalactams (penicillins, cephalosporins, and cabapenems) and to other classes of antibiotics. Antibiotic resistance classifications are shown in the table by dark red (resistant), yellow (intermediate), and white (susceptible). Sequence types (STs; right) are based on internal fragments of seven core genes (i.e., $a d k$, fumC, gyrB, icd, $m d h$, purA, and recA). Phylogenetic tree (left) is based on concatenated sequences of the seven ST core genes' fragments. Tree scale is in units of nucleotide substitutions per site.

\section{Genomic features of $E$. coli isolates}

Genome sizes of the ESBL-producing isolates assemblies ranged from 4.59 Mbp (B) to 5.35 Mbp (A) with GC content between 50.3\% (A) and 50.8\% (F and G). ST analyses identified four of the 11 isolates to be ST744 (isolates C, H, I, and J; Figure 1). The seven other isolates were identified as singleton STs, including ST34, ST46, ST69, ST70, ST224, ST328, and ST3580 (Figure 1).

A total of 46 different virulence factors were identified in the sequenced data amongst the 11 E. coli isolates (Table S2). All 11 E. coli isolates contained the ter $C$ virulence factor, responsible for tellurite resistance (Valková et al. 2007). All E. coli isolates also carried the gad virulence factor, a glutamate decarboxylase that increases survival in acidic regions of the gastrointestinal tract (Damiano et al. 2015). The other common virulence factors were sitA (with a role in transportation of $\mathrm{Fe}^{2+}$ and $\mathrm{Mn}^{2+}, n=8$ ) (Sabri et al. 2006), ompT (an outer membrane protein enabling intracellular survival, $n=6$ ) (Hejair et al. 2017), and traT (transfers protein which inhibits certain pathways, $n=6$ ) (Miajlovic and Smith 2014). 


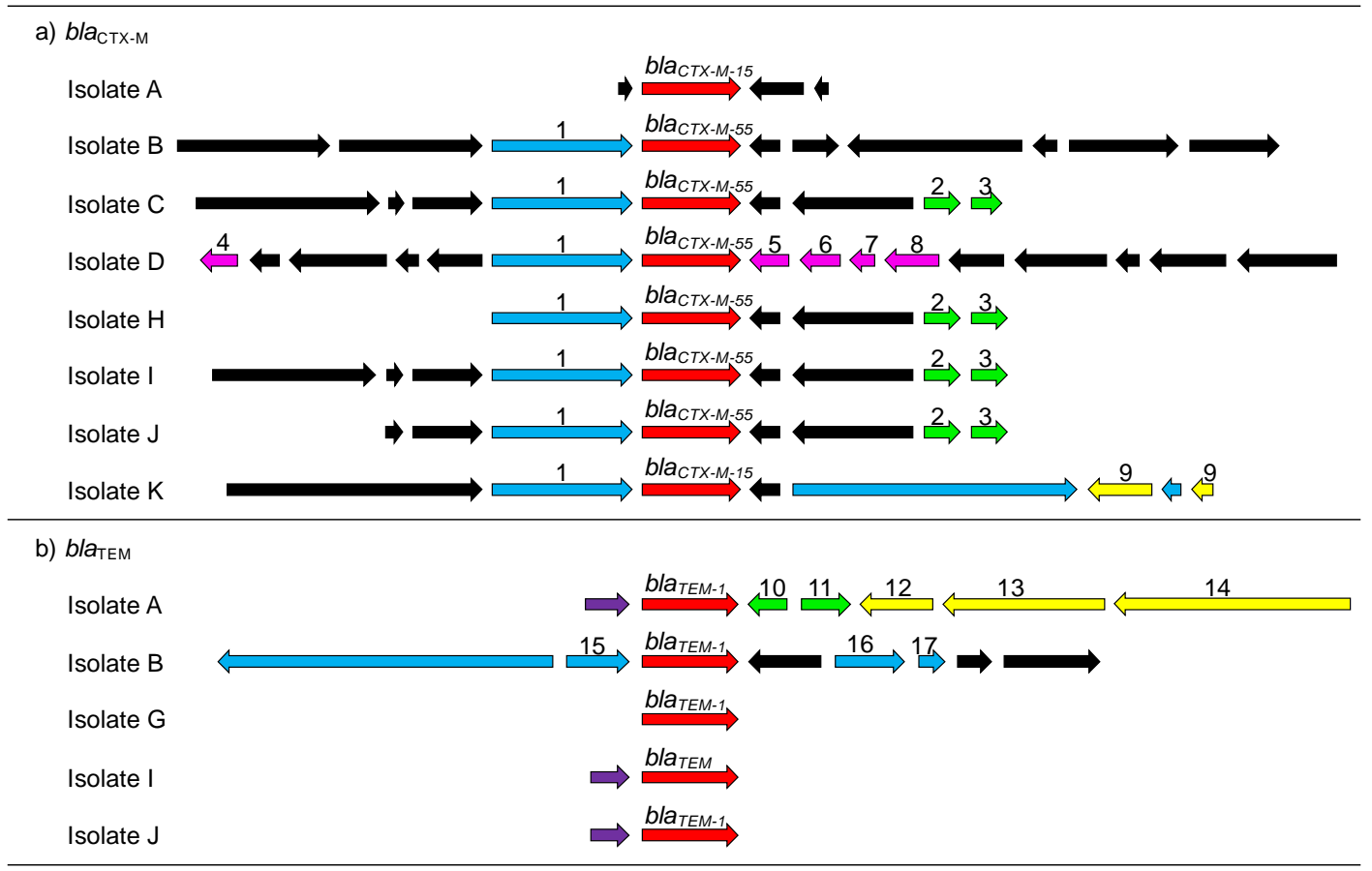

c) bla $\mathrm{CMY}$

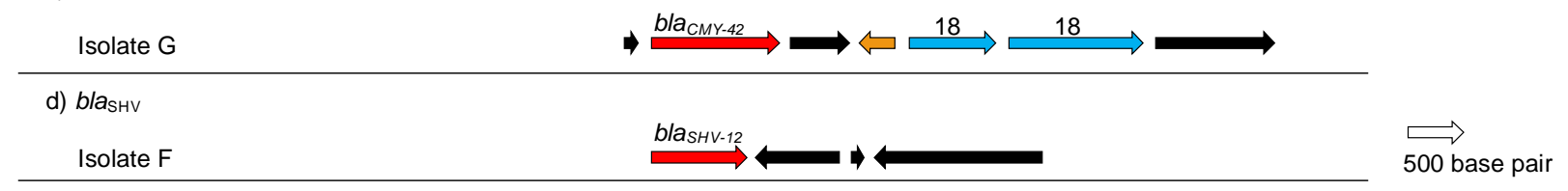

Figure 2. Gene regions for $b l a_{\mathrm{CTX}-\mathrm{M}}, b l a_{\mathrm{TEM}}, b l a_{\mathrm{CMY}}$, and $b l a_{\mathrm{SHV}}$. Arrows indicate the direction of translation, and colors indicate gene functionality (red: ESBL-encoding genes, blue: mobile genetic elements, green: heavy metal associated, yellow: $\operatorname{Tn} 7$ transposon associated, pink: possible plasmid addiction system related, purple: phage integrase associated, orange: multidrug resistance efflux pump, black: other functions). 1. transposes, 2. arsenical resistance operon, 3. arsenic resistance protein $a r s H, 4$. doc toxin, 5. YeeV toxin protein, 6. YeeU protein (antitoxin to YeeV), 7. YeeT protein, 8. YeeS protein, 9. transposase encoding genes, 10. mercuric transport protein, $M e r T, 11$. mercuric resistance operon, 12. Tn7-like transposition protein D, 13. Tn7-like transposition protein $\mathrm{C}, 14$. Tn7-like transposition protein $\mathrm{B}, 15$. transposon resolvase, 16. plasmid partitioning protein $\operatorname{ParA}, 17$. plasmid partition protein $\operatorname{ParG}, 18$. conjugal transfer protein encoding. Gene lengths are displayed to scale.

\section{ESBL-associated genes in the $E$. coli isolates}

At least one known ESBL-associated gene (i.e., bla $a_{\mathrm{CTX}}, b l a_{\mathrm{TEM}}, b l a_{\mathrm{CMY}}$, and $b l a_{\mathrm{SHV}}$ ) was found in 10 of the 11 ESBL-producing E. coli isolates (Figures 2 and 3), and five of the isolates (A, B, G, $\mathrm{I}$, and $\mathrm{J}$ ) contained two of these genes. Eight $E$. coli isolates contained $b l a_{\mathrm{CTX}-\mathrm{M}}$ genes (Figure 2a). Four of the eight isolates with bla ${ }_{\text {CTX-M }}$ gene - isolates C, H, I, and J which were all identified as ST744. These four E. coli isolates harbored arsenic resistance genes nearby the bla $_{\mathrm{CTX-M}}$ gene (labeled 2 and 3 in Figure 2a). Six of the bla $a_{\mathrm{CTX}-\mathrm{M}}$ genes were identified as subtype bla $_{\mathrm{CTX}-\mathrm{M}-55}$ (isolates B, C, D, H, I, and J) and two were identified as subtype $b l a_{\mathrm{CTX}-\mathrm{M}-15}$ (A and $\mathrm{K})$. All six of the bla $a_{\mathrm{CTX}-\mathrm{M}-55}$ carrying isolates were flanked by the same mobile genetic elements (i.e., transposase, labeled 1 in Figure 2a). The notably different gene region was from isolate D, 
which was identified as subtype bla $a_{\mathrm{CTX}-\mathrm{M}-55}$ adjacent to a set of the toxin-antitoxin yee genes and near a death-on-curing (doc) gene (Lehnherr et al. 1993; Brown and Shaw 2003).

$b_{\text {TEM }}$ genes were identified in five of the ESBL-producing E. coli isolates (Figure $2 \mathrm{~b}$ and 3). Unlike the $b l a_{\text {СTХ-м }}$ gene regions, the $b l a_{\text {TEM }}$ gene regions were not flanked by transposases. However, three of the five $b l a_{\mathrm{TEM}}$-containing isolates identified $b l a_{\mathrm{TEM}}$ adjacent to a phage integrase gene (purple arrows in Figure 2b). Moreover, bla $a_{\mathrm{CMY}}$ gene was found within only one of the isolates $(\mathrm{G})$, reported as a subtype $b l a_{\mathrm{CMY}-42}$ (Figure $2 \mathrm{c}$ ). In addition to the $b l a_{\mathrm{CMY}}$ gene, isolate $\mathrm{G}$ also carried the $b l a_{\mathrm{TEM}-1}$ gene. A $b l a_{\mathrm{SHV}}$ gene was found in isolate $\mathrm{F}$ and was reported as subtype $b l a_{\mathrm{SHV}-12}$ (Figure $2 \mathrm{~d}$ ). The $b l a_{\mathrm{CMY}}$ and $b l a_{\mathrm{SHV}}$ gene regions are similar to respective reference gene regions from other bacteria in the PATRIC database. Despite the multidrug resistance phenotype of many of the isolates, only isolate $\mathrm{G}$ had a multidrug resistance related gene (efflux pump) nearby the ESBL gene (orange arrow in Figure 2c).
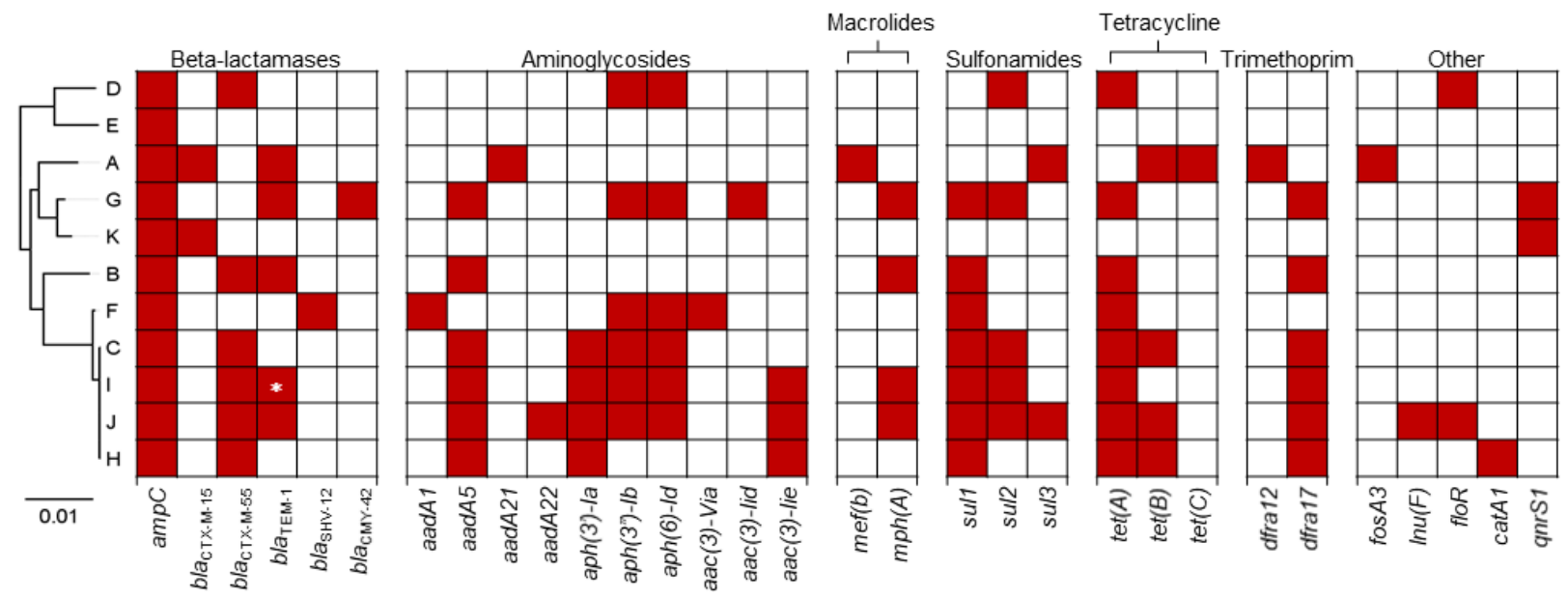

Figure 3. Antibiotic resistance genes identified in the genomes of ESBL-producing E. coli isolated from wastewater facilities in Oregon. Antibiotic resistance genes prevalence is shown in the table by dark red (present) and white (absent). Asterisk $(*)$ highlights the identified gene as TEM.

\section{Other ARGs in the $E$. coli isolates}

The analysis of sequenced data via AMRFinderPlus identified a total of 31 different ARGs belonging to 11 classes of antibiotics (Figure 3). All the 11 ESBL-producing E. coli isolates contained $\operatorname{ampC}$. AmpC beta-lactamases are cephalosporinases of clinical importance as they confer resistance to cephalothin, cefazolin, cefoxitin, most penicillins, and beta-lactamase inhibitor-beta-lactam complexes (Jacoby 2009). Results show very conserved location for ampC. The average nucleotide identity matrix between the $E$. coli isolates for the ampC is shown in Table S3. Overall, ampC genes ranged from 96.30 to $100.0 \%$ nucleotide identity. Unsurprising, isolates C, H, I, and J that were all identified as ST744 showed $100.0 \%$ similarity for ampC. Moreover, nine of the $11 \mathrm{E}$. coli isolates contained genes encoding for aminoglycoside resistance, where aadA5, aph(3')')-Ib, and aph(6)-Id were the most common genes ( $n=6$; Figure $3)$. Those same nine isolates with resistance to aminoglycosides also contained resistances to sulfonamides and tetracyclines. The most common sulfonamide resistance gene was sull $(n=7)$, followed by $\operatorname{sul2}(n=5)$. The most common tetracycline resistance gene was $\operatorname{tet}(A)(n=8)$. Seven $E$. coli isolates harbored a trimethoprim resistance gene, six of which harbored $d r f A 17$ and 
only one carried $d r f A 12$. Genes encoding resistances to fosfomycins, chloramphenicols, quinolones, and lincosamides were also detected among the E. coli isolates (Figure 3).

Comparing the resistance phenotypes and genotypes of the 11 ESBL-producing E. coli isolates, some similarities and discrepancies were observed. All isolates harbored phenotypic resistance to the tested first, second, and third generation cephalosporins (i.e., first: cefazolin, second: cefuroxime, third: ceftriaxone; Figure 1), while all but one (isolate E) carried at least one of the known ESBL genes (Figure 3). The lack of any ESBL-associated gene in isolate E suggests presence of another novel mechanism supporting cephalosporin resistance. Moreover, the two $E$. coli isolates $\mathrm{G}$ and $\mathrm{F}$ that remained susceptible to cefepime (fourth generation

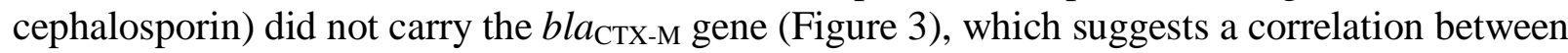
prevalence of $b l a_{\text {СтX }}$ gene and fourth generation cephalosporins. Moreover, all $11 \mathrm{E}$. coli isolates harbored the $a m p C$ gene (Figure 3) and AmpC beta-lactamases commonly mediate resistance to beta-lactamase inhibitor-beta-lactam combinations; however, only one isolate (G) showed resistance to amoxicillin/clavulanic acid, and one isolate (B) had intermediate resistance (Figure 1). Comparing resistances to aminoglycosides, results suggest the aadA5 gene (Figure 3 ) as a good indicator for prevalence of phenotypic resistances to gentamicin and tobramycin (Figure 1). For resistance to tetracycline, we observed phenotypic resistance of all but one $E$. coli isolate $(\mathrm{K})$ (Figure 1) and found one of three resistance genes $(\operatorname{tet}(A), \operatorname{tet}(B)$, and $\operatorname{tet}(C))$ in all but isolates $\mathrm{E}$ and $\mathrm{K}$, which shows these three tetracycline resistance genes as good indicators of their associated resistance phenotype.

\section{DISCUSSION}

Global spread of pathogens resistant to antibiotic treatments is a major public health issue. According to the most recent CDC report on antibiotic resistance, over 2.8 million cases of infections in the U.S. are caused by antibiotic-resistant bacteria with over 35,000 per year associated deaths (CDC, 2019). Resistance via ESBL-producing bacteria is especially concerning because of the vast number of antibiotics they confer resistance to (i.e., penicillins and cephalosporins). It is estimated that healthcare complication risk is increased by $50 \%$ if infections are caused by ESBL-producing Enterobacteriaceae (CDC, 2019). Last-resort betalactam antibiotics like carbapenems are currently used for the treatment of ESBL-producing $E$. coli infections (Hawkey and Livermore 2012); however, certain ESBL-associated genes (e.g., bla $_{\mathrm{VIM}}$ and bla $_{\mathrm{KPC}}$ ) have been shown to mediate resistance to these last resort antibiotics (Hoelle et al. 2019).

Few studies have characterized ESBL determinant genes in E. coli isolated from wastewater treatment utilities in the U.S. One such study, limited to isolates resistant to the imipenem, found a variety of ESBL-related genes including $b l a_{\mathrm{CTX}-\mathrm{M}}, b l a_{\mathrm{SHV}}$, and $b l a_{\mathrm{TEM}}$ to be prevalent in wastewater samples from seven states (Hoelle et al. 2019). Another study reported that ESBL-producing $E$. coli isolated from Colorado wastewater treatment plants expressed distinct genetic profiles compared to sewage, with wastewater samples more likely to carry bla $_{\text {CTX }}$ type genes and more likely to be MDR (Haberecht et al. 2019). Our results agree with those findings.

In this study, 11 ESBL-producing E. coli isolated from multiple wastewater treatment utilities throughout Oregon were characterized for their genetic determinants. Many of these isolates harbored MDR phenotypic resistances and carried determinant genes for a wide array of antibiotics in addition to beta-lactams including tetracycline, aminoglycosides, and quinolones. Wastewater treatment utilities are an excellent setting for the study of antibiotic resistance 
because they represent a composite sample of the community. The common MDR phenotypes in most of the isolates in this study is concerning. Moreover, four of $11 \mathrm{E}$. coli isolates (isolates C, $\mathrm{H}$, I, and J) that were all identified as ST744 carried $100.0 \%$ similarity between their average nucleotide identities for $a m p C$ while also having very similar synteny for the $b l a_{\mathrm{CTX}-\mathrm{M}-55}$ gene. Moreover, findings showed one isolate (E) with an ESBL-associated phenotype (resistance to first, second, and third generation cephalosporins) without harboring any of the known ESBL genes. This discrepancy shows the potential limitation of annotation tools for uncharacterized novel genes that confer beta-lactam resistance. As shown by the isolates encompassing multiple STs, the ESBL-positive E. coli isolated from Oregon wastewater treatment plants were phylogenetically diverse. However, the same few ESBL genes were found across multiple STs with high similarities between their average nucleotide identities of $\operatorname{ampC}$. The dissociation of core genome diversity and resistance genotypes is indicative of horizontal gene transfer. This is also supported by the colocalization of mobile genetic elements with the ESBL genes, especially bla $a_{\text {CTX-M }}$ types. The spread of beta-lactam resistance is likely not limited to conjugation via a plasmid as determinant genes could be transposed to other plasmids or chromosomes. The cooccurrences of the ESBL-associated genes with other ARGs as well as several virulence factors in these ESBL-producing E. coli isolates is concerning. Given that these isolates were collected from multiple wastewater treatment utilities in Oregon, these results indicate that ESBL resistance occurs in Oregon's wastewater systems, and the associated resistance is potentially transferable to other reservoirs, including receiving rivers and agricultural zones utilizing biosolids. Results confirm the need for further characterization of ESBL-producing Enterobacteriaceae resistome, especially in wastewater systems where confluence of municipal and clinical waste streams provide an ideal environment for the spread of ARGs.

\section{CONCLUSIONS}

This study characterizes the genotypes and phenotypes of antibiotic resistance in 11 ESBLproducing $E$. coli isolates collected from Oregon wastewater systems. Known ESBL-associated genes (i.e., bla $a_{C M Y}, b l a_{C T X}, b l a_{S H V}, b l a_{T E M}$ ) were identified in 10 of the $11 \mathrm{E}$. coli isolates with five isolates carrying two of these genes. The $\operatorname{ampC}$ gene and virulence factors were observed in all the $E$. coli isolates. Moreover, 31 different ARGs were identified across all the isolates. All $E$. coli isolates harbored phenotypic resistance to beta-lactams with eight isolates demonstrating MDR phenotypes. Six of the eleven isolates were sourced from wastewater products (biosolids and final effluents). These results demonstrate the risks of ESBL-producing E. coli in wastewater systems that can enter the environment posing a critical threat to public health.

\section{FUNDING}

This work was supported by the USDA National Institute of Food and Agriculture, Agricultural and Food Research Initiative Competitive Program, Agriculture Economics and Rural Communities, Grant No. 2018-67017-27631, and in-kind supplement from the Oregon State University's Center for Quantitative Life Sciences.

\section{REFERENCES}

Alexander, J., Hembach, N. \& Schwartz, T., 2020. Evaluation of antibiotic resistance dissemination by wastewater treatment plant effluents with different catchment areas in Germany. Scientific Reports, 10. 
Andrews, S., Krueger, F., Segonds-Pichon, A., Biggins, L., Kruger, C. \& Wingett, S., 2012. FastQC. Babraham Bioinformatics.

Ben Said, L., Jouini, A., Klibi, N., Dziri, R., Alonso, C. A., Boudabous, A., Ben Slama, K. \& Torres, C., 2015. Detection of extended-spectrum beta-lactamase (ESBL)-producing Enterobacteriaceae in vegetables, soil and water of the farm environment in Tunisia. International Journal of Food Microbiology, 203, 86-92.

Blaak, H., Lynch, G., Italiaander, R., Hamidjaja, R. A., Schets, F. M. \& de Roda Husman, A. M., 2015. Multidrug-Resistant and Extended Spectrum Beta-Lactamase-Producing Escherichia coli in Dutch Surface Water and Wastewater. (Mokrousov, I., Ed.)PLOS ONE, 10, e0127752.

Bolger, A. M., Lohse, M. \& Usadel, B., 2014. Trimmomatic: a flexible trimmer for Illumina sequence data. Bioinformatics, 30, 2114-2120.

Bradford, P. A., 2001. Extended-Spectrum ?-Lactamases in the 21st Century: Characterization, Epidemiology, and Detection of This Important Resistance Threat. CLIN. MICROBIOL. $R E V ., 14,19$.

Brown, J. M. \& Shaw, K. J., 2003. A Novel Family of Escherichia coli Toxin-Antitoxin Gene Pairs. Journal of Bacteriology, 185, 6600-6608.

Bush, K. \& Fisher, J. F., 2011. Epidemiological Expansion, Structural Studies, and Clinical Challenges of New $\beta$-Lactamases from Gram-Negative Bacteria. Annual Review of Microbiology, 65, 455-478.

Centers for Disease Control and Prevention (U.S.), 2019. Antibiotic resistance threats in the United States, 2019. Centers for Disease Control and Prevention (U.S.).

CLSI, 2020. M100 Performance Standards for Antimicrobial Susceptibility Testing A CLSI supplement for global application. 30th Edition.

Damiano, M. A., Bastianelli, D., Al Dahouk, S., Köhler, S., Cloeckaert, A., De Biase, D. \& Occhialini, A., 2015. Glutamate Decarboxylase-Dependent Acid Resistance in Brucella spp.: Distribution and Contribution to Fitness under Extremely Acidic Conditions. Applied and Environmental Microbiology, 81, 578-586.

Davis, J. J., Wattam, A. R., Aziz, R. K., Brettin, T., Butler, R., Butler, R. M., Chlenski, P., Conrad, N., Dickerman, A., Dietrich, E. M., Gabbard, J. L., Gerdes, S., Guard, A., Kenyon, R. W., Machi, D., Mao, C., Murphy-Olson, D., Nguyen, M., Nordberg, E. K. et al., 2019. The PATRIC Bioinformatics Resource Center: expanding data and analysis capabilities. Nucleic Acids Research, gkz943.

Feldgarden, M., Brover, V., Haft, D. H., Prasad, A. B., Slotta, D. J., Tolstoy, I., Tyson, G. H., Zhao, S., Hsu, C. H., McDermott, P. F., Tadesse, D. A., Morales, C., Simmons, M., Tillman, G., Wasilenko, J., Folster, J. P. \& Klimke, W., 2019. Validating the AMRFinder Tool and Resistance Gene Database by Using Antimicrobial Resistance GenotypePhenotype Correlations in a Collection of Isolates. Antimicrobial Agents and Chemotherapy, 63.

Gouy, M., Guindon, S. \& Gascuel, O., 2010. SeaView Version 4: A Multiplatform Graphical User Interface for Sequence Alignment and Phylogenetic Tree Building. Molecular Biology and Evolution, 27, 221-224.

Guindon, S., Dufayard, J. F., Lefort, V., Anisimova, M., Hordijk, W. \& Gascuel, O., 2010. New Algorithms and Methods to Estimate Maximum-Likelihood Phylogenies: Assessing the Performance of PhyML 3.0. Systematic Biology, 59, 307-321. 
Haberecht, H. B., Nealon, N. J., Gilliland, J. R., Holder, A. V., Runyan, C., Oppel, R. C., Ibrahim, H. M., Mueller, L., Schrupp, F., Vilchez, S., Antony, L., Scaria, J. \& Ryan, E. P., 2019. Antimicrobial-Resistant Escherichia coli from Environmental Waters in Northern Colorado. Journal of Environmental and Public Health, 2019, 1-13.

Haenni, M., Beyrouthy, R., Lupo, A., Châtre, P., Madec, J. Y. \& Bonnet, R., 2018. Epidemic spread of Escherichia coli ST744 isolates carrying mcr-3 and blaCTX-M-55 in cattle in France. Journal of Antimicrobial Chemotherapy, 73, 533-536.

Haghighatpanah, M., Mozaffari Nejad, A. S., Mojtahedi, A., Amirmozafari, N. \& Zeighami, H., 2016. Detection of extended-spectrum $\beta$-lactamase (ESBL) and plasmid-borne blaCTX$\mathrm{M}$ and blaTEM genes among clinical strains of Escherichia coli isolated from patients in the north of Iran. Journal of Global Antimicrobial Resistance, 7, 110-113.

Hawkey, P. M. \& Livermore, D. M., 2012. Carbapenem antibiotics for serious infections. BMJ, 344, e3236-e3236.

Hejair, H. M. A., Ma, J., Zhu, Y., Sun, M., Dong, W., Zhang, Y., Pan, Z., Zhang, W. \& Yao, H., 2017. Role of outer membrane protein $\mathrm{T}$ in pathogenicity of avian pathogenic Escherichia coli. Research in Veterinary Science, 115, 109-116.

Hoelle, J., Johnson, J. R., Johnston, B. D., Kinkle, B., Boczek, L., Ryu, H. \& Hayes, S., 2019. Survey of US wastewater for carbapenem-resistant Enterobacteriaceae. Journal of Water and Health, 17, 219-226.

Jacoby, G. A., 2009. AmpC $\beta$-Lactamases. Clinical Microbiology Reviews, 22, 161-182.

Jiang, X., Cui, X., Xu, H., Liu, W., Tao, F., Shao, T., Pan, X. \& Zheng, B., 2019. Whole genome sequencing of extended-spectrum beta-lactamase (ESBL)-producing escherichia coli isolated from a wastewater treatment plant in China. Frontiers in Microbiology, 10.

Joensen, K. G., Scheutz, F., Lund, O., Hasman, H., Kaas, R. S., Nielsen, E. M. \& Aarestrup, F. M., 2014. Real-Time Whole-Genome Sequencing for Routine Typing, Surveillance, and Outbreak Detection of Verotoxigenic Escherichia coli. Journal of Clinical Microbiology, 52, 1501-1510.

Jørgensen, S. B., Søraas, A. V., Arnesen, L. S., Leegaard, T. M., Sundsfjord, A. \& Jenum, P. A., 2017. A comparison of extended spectrum $\beta$-lactamase producing Escherichia coli from clinical, recreational water and wastewater samples associated in time and location. (Singer, A. C., Ed.)PLOS ONE, 12, e0186576.

Khorshidi-Zadeh, M., Yiu, S. Y., Nguyen, J. N., Garza, G. L., Waite-Cusic, J., Radniecki, T. R. \& Navab-Daneshmand, T., submitted. Antibiotic resistance profile of E. coli isolates in 17 municipal wastewater utilities across Oregon.

Larsen, M. V., Cosentino, S., Rasmussen, S., Friis, C., Hasman, H., Marvig, R. L., Jelsbak, L., Sicheritz-Pontén, T., Ussery, D. W., Aarestrup, F. M. \& Lund, O., 2012. Multilocus sequence typing of total-genome-sequenced bacteria. Journal of Clinical Microbiology, 50, 1355-1361.

Lehnherr, H., Maguin, E., Jafri, S. \& Yarmolinsky, M. B., 1993. Plasmid Addiction Genes of Bacteriophage P1: doc, which Causes Cell Death on Curing of Prophage, and phd, which Prevents Host Death when Prophage is Retained. Journal of Molecular Biology, 233, 414-428.

Liu, G., Bogaj, K., Bortolaia, V., Olsen, J. E. \& Thomsen, L. E., 2019. Antibiotic-Induced, Increased Conjugative Transfer Is Common to Diverse Naturally Occurring ESBL Plasmids in Escherichia coli. Frontiers in Microbiology, 10. 
Madeira, F., Park, Y. mi, Lee, J., Buso, N., Gur, T., Madhusoodanan, N., Basutkar, P., Tivey, A. R. N., Potter, S. C., Finn, R. D. \& Lopez, R., 2019. The EMBL-EBI search and sequence analysis tools APIs in 2019. Nucleic Acids Research, 47, W636-W641.

Manaia, C. M., Rocha, J., Scaccia, N., Marano, R., Radu, E., Biancullo, F., Cerqueira, F., Fortunato, G., Iakovides, I. C., Zammit, I., Kampouris, I., Vaz-Moreira, I. \& Nunes, O. C., 2018. Antibiotic resistance in wastewater treatment plants: Tackling the black box. Environment International, 115, 312-324.

Miajlovic, H. \& Smith, S. G., 2014. Bacterial self-defence: how Escherichia coli evades serum killing. FEMS Microbiology Letters, 354, 1-9.

Palucha, A., Mikiewicz, B., Hryniewicz, W. \& Gniadkowski, M., 1999. Concurrent outbreaks of extended-spectrum $\beta$-lactamase-producing organisms of the family Enterobacteriaceae in a Warsaw hospital. Journal of Antimicrobial Chemotherapy, 44, 489-499.

Park, Y., Kang, H. K., Bae, I. K., Kim, J., Kim, J. S., Uh, Y., Jeong, S. H. \& Lee, K., 2009. Prevalence of the Extended-Spectrum $\beta$-Lactamase and qnr Genes in Clinical Isolates of Escherichia coli. Annals of Laboratory Medicine, 29, 218-223.

Paulshus, E., Thorell, K., Guzman-Otazo, J., Joffre, E., Colque, P., Kühn, I., Möllby, R., Sørum, H. \& Sjöling, A., 2019. Repeated Isolation of Extended-Spectrum- $\beta$-Lactamase-Positive Escherichia coli Sequence Types 648 and 131 from Community Wastewater Indicates that Sewage Systems Are Important Sources of Emerging Clones of Antibiotic-Resistant Bacteria.

Riquelme, M. V., Garner, E., Gupta, S., Metch, J., Zhu, N., Blair, M. F., Arango-Argoty, G., Maile-Moskowitz, A., Li, A., Flach, C. F., Aga, D. S., Nambi, I., Larsson, D. G. J., Bürgmann, H., Zhang, T., Pruden, A. \& Vikesland, P. J., 2021. Wastewater Based Epidemiology Enabled Surveillance of Antibiotic Resistance, p. 2021.06.01.21258164.

Sabri, M., Léveillé, S. \& Dozois, C. M. Y., 2006. A SitABCD homologue from an avian pathogenic Escherichia coli strain mediates transport of iron and manganese and resistance to hydrogen peroxide. Microbiology, 152, 745-758.

Schages, L., Wichern, F., Kalscheuer, R. \& Bockmühl, D., 2020. Winter is coming - Impact of temperature on the variation of beta-lactamase and mcr genes in a wastewater treatment plant. Science of The Total Environment, 712, 136499.

Schmiege, D., Zacharias, N., Sib, E., Falkenberg, T., Moebus, S., Evers, M. \& Kistemann, T., 2021. Prevalence of multidrug-resistant and extended-spectrum beta-lactamase-producing Escherichia coli in urban community wastewater. Science of The Total Environment, 785, 147269.

Schwaber, M. J., Navon-Venezia, S., Schwartz, D. \& Carmeli, Y., 2005. High levels of antimicrobial coresistance among extended-spectrum- $\beta$ - lactamase-producing Enterobacteriaceae. Antimicrobial Agents and Chemotherapy, 49, 2137-2139.

Schwaber, M. J., Navon-Venezia, S., Kaye, K. S., Ben-Ami, R., Schwartz, D. \& Carmeli, Y., 2006. Clinical and Economic Impact of Bacteremia with Extended- Spectrum- $\beta$ Lactamase-Producing Enterobacteriaceae. Antimicrobial Agents and Chemotherapy, 50, 1257-1262.

Severin, J. A., Mertaniasih, N. M., Kuntaman, K., Lestari, E. S., Purwanta, M., Lemmens-Den Toom, N., Duerink, D. O., Hadi, U., van Belkum, A., Verbrugh, H. A. \& Goessens, W. H., 2010. Molecular characterization of extended-spectrum $\beta$-lactamases in clinical Escherichia coli and Klebsiella pneumoniae isolates from Surabaya, Indonesia. Journal of Antimicrobial Chemotherapy, 65, 465-469. 
medRxiv preprint doi: https://doi.org/10.1101/2021.11.15.21266365; this version posted November 16, 2021. The copyright holder for this preprint (which was not certified by peer review) is the author/funder, who has granted medRxiv a license to display the preprint in perpetuity.

It is made available under a CC-BY-ND 4.0 International license.

Sidjabat, H. E., Paterson, D. L., Adams-Haduch, J. M., Ewan, L., Pasculle, A. W., Muto, C. A., Tian, G. B. \& Doi, Y., 2009. Molecular Epidemiology of CTX-M-Producing Escherichia coli Isolates at a Tertiary Medical Center in Western Pennsylvania. Antimicrobial Agents and Chemotherapy, 53, 4733-4739.

Turkovicova, L., Smidak, R., Jung, G., Turna, J., Lubec, G. \& Aradska, J., 2016. Proteomic analysis of the TerC interactome: Novel links to tellurite resistance and pathogenicity. Journal of Proteomics, 136, 167-173.

Valková, D., Valkovičová, L., Vávrová, S., Kováčová, E., Mravec, J. \& Turňa, J., 2007. The contribution of tellurite resistance genes to the fitness of Escherichia coli uropathogenic strains. Open Life Sciences, 2, 182-191.

Wirth, T., Falush, D., Lan, R., Colles, F., Mensa, P., Wieler, L. H., Karch, H., Reeves, P. R., Maiden, M. C., Ochman, H. \& Achtman, M., 2006. Sex and virulence in Escherichia coli: an evolutionary perspective. Molecular Microbiology, 60, 1136-1151. 